\title{
AGRICULTURA FAMILIAR, POLÍTICAS PÚBLICAS E CIDADANIA: CONEXÕESCONSTRUÍDAS A PARTIR DA OPERACIONALIZAÇÃO DO PROGRAMA NACIONAL DE ALIMENTAÇÃO ESCOLAR'
}

\section{FAMILY FARM, PUBLIC POLICIES AND CITIZENSHIP: CONNECTIONS BUILT FROM THE OPERATION OF THE PROGRAM NATIONAL SCHOOL FEEDING}

\author{
Danielle Wagner \\ Universidade Federal do Oeste do Pará - Santarém - PA - Brasil \\ Ivaldo Gehlen \\ Universidade Federal do Rio Grande do Sul - Porto Alegre - RS - Brasil \\ Glauco Schultz \\ Universidade Federal do Rio Grande do Sul - Porto Alegre - RS - Brasil
}

\begin{abstract}
Resumo: Neste artigo analisa-se o processo de usufruto das prerrogativas dispostas no Programa Nacional da Alimentação Escolar- PNAE pelos agricultores familiares fornecedores de produtos ao Programa. A discussão apresentada foi feita a partir de revisão da literatura sobre a participação da Agricultura Familiar no PNAE e de pesquisa de campo realizada em 2013 e 2014 sobre as experiências de acesso dos agricultores na política de fornecimento de produtos para a alimentação escolar nos municípios de Brasil Novo, estado do Pará, e Cachoeira do Sul, Rio Grande do Sul. O estudo mostra que o fornecimento de produtos da agricultura familiar para a alimentação escolar não expressa necessariamente a apropriação do direito à venda pelos agricultores fornecedores. A participação dos agricultores familiares no PNAE não pode ser considerada apenas no contexto da geração de renda, uma vez que a aquisição de produtos não está relacionada apenas ao mercado. Nesse sentido, o reconhecimento social dos mesmos como produtores de alimentos, a apropriação do direito conquistado e as mudanças nas estruturas de oportunidades também são elementos importantes. Constatou que, apesar de incongruências que por ventura aparecem no processo de compra e venda de produtos da Agricultura Familiar através
\end{abstract}

'Este artigo é construído a partir da tese de doutorado da primeira autora, orientada pelos coautores. 
dos programas governamentais, está ocorrendo modificações na organização sociopolítica e produtiva dos atores. Conclui-se que a implementação das prerrogativas do PNAE, a partir da Lei 11.947/2009, ampliou as oportunidades sociais dos agricultores familiares, propiciando e fomentando novas possibilidades comerciais, novos modos de fazer agricultura, de organização social e a conquista de nova forma de cidadania.

Palavras-Chave: Mercados institucionais. Desenvolvimento Rural. PNAE.

Abstract: This paper aims to analyze the process of enjoyment of prerogatives set forth in School Feeding National Program -PNAE by family farmers to program product suppliers, to discuss the PNAE the establishment of thresholds as an instrument of citizenship. The discussions presented are based on literature review on the participation of Family Farming in the PNAE and field research on the farmers access experience to supply product policy of school feeding in the municipalities of Brasil Novo, state of Pará, and Cachoeira do Sul, Rio Grande do Sul. The study show that the supply of family farming products for school feeding does not necessarily express the appropriation of the right to sale by suppliers farmers. The participation of farmers in PNAE can not be considered only in the context of income, since the acquisition of products is not only related to the market. In this sense, social recognition the same such as food producers, ownership of the conquered right and changes in opportunities are also important elements of structures. Despite the inconsistencies that perhaps appear in the process of buying and selling of Family Agriculture through government programs, there were changes in the socio-political organization and productive actors, pointing out that the implementation of PNAE presents to family farmers new market opportunities, of ways of doing agriculture, social organization and to be a citizen.

Keywords: Institutional Markets. Rural Development. PNAE.

\section{Introdução}

Na última década, os programas estatais de aquisição de alimentos favoreceram a inclusão da Agricultura Familiar nos chamados mercados institucionais, possibilitando a democratização da distribuição de recursos públicos. Conforme os estudos de Turpin (2008), Grisa (2012) e Triches e Schneider (2010a, 2010b, 2012), as mudanças ocorridas no processo de compras públicas criaram transformações nas formas de produção e consumo de alimentos, mostrando-se como uma alternativa de mercado para os agricultores familiares.

O processo de compra e venda de produtos da Agricultura Familiar destinados à alimentação escolar, através do Programa Nacional de Alimentação Escolar- PNAE, tem gerado diversos resultados. Os trabalhos que abordam tal tema, tais como os de Turpin, (2008; 2009), 
Triches (2010), Triches; Schneider (2010b); Triches; Fröelich; Schneider (2011, 2013), Triches; Schneider (2012), Fornazier (2014) e Agne (2014), destacam como aspectos positivo a inserção dos agricultores em novos mercados, a valorização $d a$ produção de alimentos, a reconstrução de cadeias alimentares curtas, além das contribuições com a segurança alimentar dos agricultores e do alunado atendido.

Os estudos, também, apontam que as principais dificuldades na execução dessa política são: a falta de compreensão da legislação pelos compradores e pelos fornecedores; a burocracia da operacionalização; o não cumprimento dos agricultores das exigências legais do PNAE e de outras legislações, como a sanitária; a falta de vontade política dos gestores, principalmente locais (TRICHES; SCHNEIDER, 2010b; TRICHES; FRÖELICH; SCHNEIDER 2011 ; TRICHES; SCHNEIDER, 2012; BACCARIN et al., 2012; SARAIVA et al., 2013; AGNE, 2014; FORNAZIER, 2014).

Frente a esses resultados, vale considerar que o processo de operacionalização da inserção dos produtos da Agricultura Familiar na alimentação escolar, conforme disposto no Artigo 14 da Lei 11.947/2009, ainda está em curso. Como citado acima, os estudos sobre essa temática apontam diversos aspectos que influenciam a operacionalização do PNAE, havendo lacunas quanto à apropriação das prerrogativas concernentes ao acesso ao recurso dessa política pública, principalmente sobre as formas como elas - e as normas que as estruturam - têm sido ressignificadas e objetivadas através das práticas dos agricultores fornecedores. Dessa forma, torna-se importante problematizar o processo de implementação da referida Lei no que concerne à efetividade das políticas e os elementos constitutivos da cidadania. Para Dahrendorf (1992, p. 47), a cidadania é "[...] um papel social real", que se estrutura em um conjunto de direitos e obrigações. A cidadania resulta da inclusão do indivíduo na sociedade da qual faz parte devendo ser reconhecido como membro, usufruindo dos direitos de todos os cidadãos. O exercício da cidadania incide na valorização de um modo de vida e no sentimento de pertencimento a um determinado grupo social e/ou território.

Partindo-se do entendimento de que a inserção dos produtos da Agricultura Familiar na alimentação escolar amplia a possibilidade de constituição da cidadania, neste artigo objetiva-se analisar o processo de usufruto das prerrogativas dispostas no PNAE pelos agricultores 
familiares fornecedores de produtos ao programa, de modo a discutir os limiares da constituição do PNAE como instrumento de cidadania dos mesmos. Além do aporte teórico e de revisão da literatura, a discussão apresentada relaciona-se de pesquisa de campo sobre a experiência de grupos de agricultores familiares situados nos municípios de Brasil Novo, estado do Pará - PA e de Cachoeira do Sul, no estado do Rio Grande do Sul - RS, no fornecimento de produtos ao Programa.

$O$ texto consta de uma introdução, quatro seções e das considerações finais. A seguir é apresentada a metodologia adotada na pesquisa de campo, baseada em conceitos e ferramentas de coleta e da análise de dados. Na segunda seção, contextualiza-se emergência do PNAE, enquanto política pública de fortalecimento da Agricultura Familiar. Na seção seguinte, é analisado o processo de apropriação das prerrogativas previstas no PNAE pelos agricultores fornecedores, focando as nuances presentes nas ações dos atores na criação e no usufruto de oportunidades sociais. Na quarta seção, discute-se o PNAE, enquanto política pública assegurada aos agricultores familiares.

\section{0 percurso da pesquisa: conjunções entre autores, atores e processos}

Dahrendorf (1992, p. 29) considera que "a cidadania é um conjunto de prerrogativas", e ressalta que seu exercício depende das opções escolhidas pelos indivíduos. De acordo com o autor, a prerrogativa constitui-se num privilégio acessível a um segmento social, legitimada por normas sociais ou por um marco legal. Os direitos fundamentais são considerados como prerrogativas, uma vez que "incluem direitos constitucionalmente garantidos, associados à participação como membro de uma sociedade" (DAHRENDORF, 1992, p. 27). Para o autor, a cidadania constitui-se num conjunto de prerrogativas e de provimentos, pois, a condição de cidadão engloba fatores políticos, sociais e econômicos.

A conexão entre prerrogativas e provimentos assemelha-se ao que Sen (2000) chamou de liberdades substantivas. Para esse autor, as liberdades substantivas são centrais no processo de desenvolvimento, uma vez que se referem às condições para que os indivíduos evitem privações. Na análise feita por Dahrendorf (1992), os privilégios obtidos através de prerrogativas, quando associados a provimentos disponíveis, são mecanismos de superação da privação. Nesse sentido, os 
provimentos, enquanto pré-condições para acessar as prerrogativas, podem ser considerados oportunidades sociais.

Considerando que, de acordo com Dahrendorf (1992), o acesso às prerrogativas depende dos provimentos, neste trabalho a distinção entre prerrogativas e provimentos tem utilidade analítica e operativa. A utilidade analítica ocorre à medida que a questão em análise faz referência à conquista de direitos (prerrogativas) e ao acesso aos direitos conquistados (provimentos). Tornam-se operativos quando são mobilizados para distinguir o direito dos agricultores familiares à política de alimentação escolar do acesso que esses atores têm de fato feito, ou seja, as estratégias de venda de seus produtos para o PNAE.

Para fins operativos, compreende-se como conjunto de prerrogativas os diversos direitos dos fornecedores considerados agricultores familiares, conforme a Lei $\mathrm{n}^{0} 11.326 / 2006$ e como agricultores assentados da reforma agrária. Tais direitos são documentos pessoais, do estabelecimento agrícola e do empreendimento, direito à infraestrutura (estrada, energia, habitação), crédito agrícola, assistência técnica, dentre outros. Os provimentos são os recursos materiais e financeiros, bens simbólicos e instrumentos disponíveis e/ou necessários para o acesso às prerrogativas, como os fatores de produção (terra para cultivo, capital para investimento, mão de obra), a informação sobre processos burocráticos (documentos), instrumentos de trabalho (maquinários, instalações, veículos de transporte) e demais instrumentos e infraestrutura, necessários para a produção, processamento (se houver) e entrega dos produtos demandados para a alimentação escolar.

Além dos conceitos de prerrogativas e provimentos, para fundamentar a análise proposta, optou-se por utilizar o conceito de agência, pois, ele contribui para a compreender a participação dos indivíduos na sociedade e, desta forma, o exercício da cidadania. Segundo Giddens (1991), Sen (2000) e Long (2007), a condição de agente decorre do fato do indivíduo (individual ou coletivo), estar diretamente envolvido em determinado processo ou fato social, por assumir determinados papéis e ter poder de interferir. O conceito de agência está associado às noções de sistemas abstratos e sistemas de peritos, discutidos por Giddens (1991). Segundo este autor (1991, p. 39), "todas as formas de vida social são parcialmente constituídas pelo 
conhecimento que os atores têm delas". Na sociedade moderna, segundo este autor, os indivíduos ou grupos são constrangidos por estruturas sociais, o que os torna atores leigos. Os constrangimentos ocorrem porque os atores estão envolvidos em sistemas abstratos que favorecem o desencaixe das relações sociais, mas agem de acordo com a confiança naqueles que operacionalizam os sistemas" (GIDDENS, 1991).

Partindo dessa perspectiva analítica, a apropriação das prerrogativas por parte dos agricultores beneficiados foi analisada a partir da provisão e gestão que as famílias fizeram dos provimentos disponíveis e mobilizados frente às prerrogativas dispostas na Lei $\mathrm{n}^{\circ}$ $11.947 / 2009$, das normas estabelecidas nas Resoluções $n^{\circ} 38 / 2009$ e $n^{\circ} 26 / 2013$ e demais exigências feitas pelos gestores públicos para ingresso no mercado institucional. Para se compreender as práticas sociais dos agricultores familiares no exercício de direitos conquistados, através de políticas públicas, é preciso compreender o processo de mudanças nas estruturas de prerrogativas na esfera local e dos provimentos que possibilitam exercê-los.

A pesquisa de campo desenvolvida focou-se na organização do processo de aquisição dos produtos da Agricultura Familiar para o PNAE (burocrática, social e produtiva). Foram privilegiadas as prerrogativas disponíveis e acessadas pelos agricultores fornecedores, os provimentos necessários e mobilizados (ou não) por eles para atender à demanda.

A pesquisa foi realizada entre os meses de setembro de 2013 e maio de 2014. Priorizou-se as experiências de grupos de agricultores fornecedores de produtos para alimentação escolar, situados nos municípios de Brasil Novo, no estado do Pará e no município de Cachoeira do Sul, Rio Grande do Sul2.A população da pesquisa foi composta pelos atores envolvidos no processo de aquisição de produtos da Agricultura Familiar para a alimentação escolar: gestores públicos, parceiros e os associados da Associação dos Produtores Rurais e Urbanos Carlos Pena Filho - APRUCAPEFI e da Associação dos Feirantes e Hortifrutigranjeiros de Brasil Novo - AFEBRAN em Brasil Novo e à

\footnotetext{
${ }^{2}$ Ressalta-se que parte da pesquisa de campo realizada em Brasil Novo contou com o apoio logístico do projeto "Monitoramento e avaliação de políticas públicas para gestão de territórios na Amazônia paraense", vinculado ao Núcleo de Extensão em Desenvolvimento Territorial (NEDET- UFPA) sob coordenação do professor Miqueias Calvi e financiado pelo CNPQ/MDA.
} 
Associação dos Produtores Rurais de Cachoeira do Sul- APRCS em Cachoeira do Sul. Foram realizadas 56 entrevistas e a análise dos dados foi realizada através da técnica de análise de conteúdo (BARDIN, 1977; MINAYO, 2008).

\section{PNAE no contexto das Políticas Públicas de Desenvolvimento Rural no Brasil: prerrogativas em construção}

As discussões sobre a alimentação escolar realizaram-se no quadro do debate sobre o direito humano à alimentação adequada (saudável e equilibrada). Esse tema começou a ser tratado no Brasil na década de 1930 no âmbito das discussões sobre a deficiência nutricional e a fome (PEIXINHO, 2013). A história do PNAE no Brasil teve inicio na década de 1950 como resultado desse debate e sob a inspiração de Josué de Castro, quando o Ministério da Saúde lançou o Plano Nacional de Alimentação e Nutrição. Esse plano teve como objetivo arrecadar alimentos para garantir que as crianças de escolas públicas tivessem acesso garantido, ao menos, a uma refeição ao dia (TURPIN, 2008; TRICHES, 2010; BRASIL, [2013?]a; PEIXINHO, 2013). Em 1955, o plano foi transformado no PNAE, cuja função era garantir a transferência de recursos financeiros do governo federal para que os estados e municípios viabilizassem a oferta de alimentação aos alunos da rede de educação básica ${ }^{3}$, matriculados em escolas públicas e filantrópicas (BRASIL, [2013?]a). O PNAE foi criado com o objetivo de "atender as necessidades nutricionais dos alunos durante sua permanência em sala de aula, contribuindo para o crescimento, o desenvolvimento, a aprendizagem e o rendimento escolar dos estudantes, bem como promover a formação de hábitos alimentares saudáveis" (BRASIL, [2013?]a, não paginado).

Até meados da década de 1990 a compra dos gêneros alimentícios era centralizada pelo Governo Federal. Os alimentos eram comprados via licitação, estocados em Brasília e distribuídos para todas as escolas em todo território brasileiro. Devido ao tempo entre aquisição e o consumo dos alimentos, a alimentação era integrada por produtos industrializados e processados, como leite em pó, achocolatados,

\footnotetext{
3 Educação básica inclui as seguintes modalidades de educação formal: educação infantil, ensino fundamental, ensino médio e educação de jovens e adultos.
} 
biscoitos e carne enlatada (TURPIN, 2008; PEIXINHO, 2013; TRICHES, 2010).

A partir da pressão do Conselho Nacional de Saúde- CONSEA, através da Lei $n^{\circ} 8.913$, de 12 de julho de 1994, a gestão dos recursos da alimentação escolar foi descentralizada (CECANE, 2012). Através de convênios celebrados entre União (Secretaria de Educação do Distrito Federal) e as Secretarias de Educação dos estados, os recursos federais passaram a ser administrados por gestores públicos estaduais e municipais, que realizavam as compras localmente. Sendo os recursos aplicados, exclusivamente, na compra de alimentos (CECANE, 2012; PEIXINHO, 2013).

Face às dificuldades de gerenciamento dos recursos financeiros destinados à educação, em 1998 o Governo Federal criou o Fundo Nacional de Desenvolvimento da Educação- FNDE, autarquia vinculada ao extinto Ministério da Educação e Cultura - MEC, que passou a gerir os recursos da alimentação escolar, fazendo a transferência para todos os municípios e Secretarias Estaduais de Educação, sem a necessidade de celebração de convênios. Em 2001, o Governo Federal determinou que, no mínimo $70 \%$ das verbas repassadas pelo FNDE aos estados e municípios, fossem aplicadas na compra de produtos básicos condizentes com os hábitos e produção agrícola local. Apesar da intenção de fomentar a aquisição dos gêneros alimentícios locais, a compra dos mesmos continuou a ser realizada segundo a Lei de Licitações, o que significou modificações nas compras, mas não dos fornecedores.

Em 2003, a criação do Programa de Aquisição de Alimentos - PAA provocou mudanças significativas no cardápio da alimentação escolar. A adoção da modalidade de Compra Direta permitiu que os gestores públicos municipais comprassem os produtos da Agricultura Familiar e os distribuíssem às escolas públicas e filantrópicas, ampliando a inserção de alimentos in natura no cardápio. De acordo com os estudos de Turpin (2008, 2009), essa nova prática contribuiu para a valorização de hábitos alimentares regionais, a valorização da Agricultura Familiar e para a educação alimentar.

Tal prática foi fortalecida em 2006 quando as novas diretrizes do PNAE ressaltavam a promoção da alimentação saudável e adequada, a educação alimentar e nutricional e o apoio ao desenvolvimento 
sustentável. Essa nova ênfase do Programa resultou de amplas discussões no contexto do CONSEA e da convergência de interesses de diversos atores (gestores públicos, organizações não governamentais, representações de agricultores familiares, movimentos sociais e pesquisadores) em estimular a segurança alimentar e nutricional dos alunos e a Agricultura Familiar (BELIK, 2012). A aquisição de produtos dos agricultores familiares para o PNAE, além de fortalecer a segurança alimentar dos alunos e dos agricultores, dinamizou a economia local, como apontam os estudos de Triches (2010) e Triches e Schneider (2012).

Em sequência aos debates sobre Segurança Alimentar e Nutricional - SAN- e sobre ações voltadas ao combate à pobreza, em 2009 foi promulgada a Lei Federal $n^{0} 11.947$, de 16 de junho ${ }^{4}$. A nova Lei estabeleceu modificações significativas na proposição e execução do PNAE, constituindo-se instrumento de desenvolvimento local, por incentivar a produção sustentável e comercialização de alimentos locais (BRASIL, 2009a).

O Artigo 14 da referida Lei determinou que a alimentação escolar, municípios e estados aplicassem, no mínimo 30\% dos recursos financeiros repassados pelo FNDE, na compra de gêneros alimentícios da Agricultura Familiar, sem necessidade de licitação:

Art. 14. Do total dos recursos financeiros repassados pelo FNDE, no âmbito do PNAE, no mínimo 30\% (trinta por cento) deverão ser utilizados na aquisição de gêneros alimentícios diretamente da Agricultura Familiar e do empreendedor familiar rural ou de suas organizações, priorizando-se os assentamentos da reforma agrária, as comunidades tradicionais indígenas e comunidades quilombolas (BRASIL, 2009a).

O disposto no Artigo 14 estabeleceu a exigência de que o cardápio ofertasse, no mínimo, três porções de frutas e hortaliças por semana, privilegiasse as aquisições de produtos agrícolas produzidos localmente e, preferencialmente, orgânicos e/ou agroecológicos. Essas

4 Dispõe sobre o atendimento da alimentação escolar e do Programa Dinheiro Direto na Escola aos alunos da educação básica; altera as Leis nos 10.880, de 9 de junho de 2004, 11.273, de 6 de fevereiro de 2006, 11.507, de 20 de julho de 2007; revoga dispositivos da Medida Provisória no 2.178-36, de 24 de agosto de 2001, e a Lei no 8.913 , de 12 de julho de 1994; e dá outras providências. 
exigências favoreceram, não apenas a qualidade da alimentação escolar e dinamizaram a economia local ${ }^{5}$.

Para o exercício 2016, o orçamento do PNAE foi de, aproximadamente, $\mathrm{R} \$ 3,5$ bilhões, destinados a atender cerca de 43 milhões de estudantes da educação básica, jovens e adultos (BRASIL, 2016), sem contabilizar a contrapartida facultada aos municípios. Nos termos da Lei $n^{\circ} 11.947 / 2009$, no mínimo 30\% desse valor ( $\$$ \$ 1,05 bilhão), deve ser investido na aquisição de gêneros alimentícios da Agricultura Familiar. Na prática, isso significa a inserção de, no mínimo, 52.500 unidades de produção familiar no processo de fornecimento de produtos para a alimentação escolar.

De acordo com Saraiva et al. (2013), em 2010, ano em que a Lei $n^{\circ} 11.947 / 2009$ entrou em vigor, 47,4\% dos municípios brasileiros, que prestaram contas dos recursos recebidos do FNDE, realizaram aquisições de gêneros alimentícios de agricultores familiares para a alimentação escolar. Segundo as autoras, o percentual médio de compra dos municípios foi abaixo do exigido em lei $(22,7 \%$ do valor disponibilizado pelo FNDE).

A partir da análise dos pareceres apresentados pelos Conselhos de Alimentação Escolar - CAEs dos municípios que prestaram contas do exercício 2010, Saraiva et al. (2013) consideraram que, a não aplicação dos $30 \%$ do recurso na compra de produtos da Agricultura Familiar resultou, principalmente, fornecimento irregular dos agricultores fornecedores $(21,10 \%$ das justificativas) e da falta de interesse dos agricultores, o atraso das prefeituras em elaborar a Chamada Pública e à falta de oferta de produtos, devido aos agricultores destinarem todos os gêneros para o PAA.

5 Consta no Artigo $2^{\circ}$ da Resolução $n^{\circ}$ 26/2013 como diretrizes da Alimentação Escolar: " $V$ - o apoio ao desenvolvimento sustentável, com incentivos para a aquisição de gêneros alimentícios diversificados, produzidos em âmbito local e preferencialmente pela Agricultura Familiar e pelos empreendedores familiares rurais, priorizando as comunidades tradicionais indígenas e de remanescentes de quilombos; e VI - o direito à alimentação escolar, visando garantir a segurança alimentar e nutricional dos alunos, com acesso de forma igualitária, respeitando as diferenças biológicas entre idades e condições de saúde dos alunos que necessitem de atenção específica e aqueles que se encontrem em vulnerabilidade social" (BRASIL, 2013a, não paginado). 
A partir de 200, ocorreram mudanças na regulamentação do Artigo 14 da Lei $n^{0} 11.947 / 2009$, sobre a operacionalização das compras. Normas, diretrizes e resoluções burocratizaram excessivamente o processo de compra e venda de produtos alimentícios da Agricultura Familiar para a alimentação escolar.

Conforme a Lei $\mathrm{n}^{\circ} 11.947 / 2009$, a Resolução CD/FNDE n³8/2009 e Resolução CD/FNDE n² 26/2013 e a Resolução CD/FNDE $n^{\circ} 26 / 2015$, esse processo envolve diversas etapas. Disso resulta a negociação entre os atores envolvidos (gestores públicos, organizações da agricultura familiar, agricultores familiares, órgãos de Assistência Técnica e Extensão Rural - ATER, dentre outros) para a decisão relativa ao cardápio, o preço dos produtos, a qualidade, a forma de apresentação e embalagem dos produtos a serem vendidos, o cronograma de entrega, a chamada pública e outras etapas e instrumentos importantes no processo.

Até março de 2015, a operacionalização da compra foi regulamentada pela Resolução CD/FNDE $n^{\circ} 26$ de 2013, que revogou a Resolução CD/FNDE $n^{\circ}$ 38/2009. De acordo com o disposto nessa resolução, para que o agricultor familiar fosse fornecedor do PNAE deveria dispor da Declaração de Aptidão ao PRONAF6- DAP. Se os agricultores fornecessem os produtos através de cooperativas e associações, seria exigido, além da DAP física, as organizações proponentes possuíssem a DAP jurídica (BRASIL, 2013d). O limite individual de venda do agricultor familiar, independente da modalidade do grupo, era de $\mathrm{R} \$ 20.000,00$ por DAP/ano7.

De acordo com as normativas, os produtos da Agricultura Familiar podem ser comprados com dispensa de licitação. Nesse caso, os gestores públicos efetuam a compra por um processo diferenciado e específico para esse público, que envolve lançamento de Chamada Pública, seleção de projetos de venda (propostas), assinatura de contrato e comprovação de entrega dos produtos.

Para e organizar o processo de informação sobre os produtos a serem comprados pela Entidade Executora, bem como a seleção dos

\footnotetext{
6 Programa Nacional de Fortalecimento da Agricultura Familiar.

7 Na promulgação da Resolução $n^{\circ} 38 / 2009$, foi estabelecido o limite máximo de $R \$$ 9.000,00 DAP/ano. No entanto, após reivindicação das organizações da Agricultura Familiar, em 2012 o limite foi alterado para $\mathrm{R} \$ 20.000,00 \mathrm{DAP} /$ ano.
} 
fornecedores, devia-se fazer uma Chamada Pública. Nesse instrumento, elaborado com base nos produtos elencados no cardápio elaborado por um Responsável Técnico (Nutricionista), deveriam constar todas as informações necessárias para orientar os interessados em apresentar projetos de venda, tais como período de início e fim do chamamento público, sua finalidade, os gêneros alimentícios a serem entregues à Entidade Executora, especificando unidades, quantidades e preços, cronograma e local de entrega dos produtos, apresentação de amostra dos produtos para avaliação prévia e prazos para recebimento do projeto de venda.

O preço a ser pago pelos produtos da Agricultura Familiar deve constar na Chamada Pública. Na formulação do preço, a Entidade Executora necessita considerar o preço médio pesquisado em três mercados em âmbito local, territorial, estadual ou nacional, priorizando-se a feira do produtor da Agricultura Familiar, quando houver ${ }^{8}$, e todos os insumos necessários para o fornecimento dos produtos, como frete, embalagens, encargos (BRASIL, 2013d). No caso de o valor total de repasse do FNDE para execução do PNAE ser superior a $\mathrm{R} \$ 700.000,00$ (setecentos mil reais) por ano, fica a critério da Entidade Executora aceitar propostas apenas de organizações com DAP Jurídica, desde que isto seja previsto na chamada pública (BRASIL, 2013d).

Conforme o disposto no Artigo $n^{\circ} 22$ da Resolução $n^{\circ}$ 26/2013, a apresentação de propostas pelos agricultores interessados deve ser feita através do Projeto de Venda. Nos projetos apresentados individualmente, através de grupo formal ou grupo informal, devem ser especificados o nome do proponente, os fornecedores e produtos (produto, unidade, quantidade, preço e valor total), os mecanismos de acompanhamento das entregas dos produtos, documentos de identificação do fornecedor proponente e assinatura.

A forma de elaboração do projeto de venda e a documentação a ser apresentada, em resposta à chamada pública, dependem do grupo proponente. Os agricultores organizados em grupos informais devem

\footnotetext{
8 De acordo com a Resolução $n^{\circ} 38 / 2009$ (Artigo 23, Parágrafo $6^{\circ}$ ), os gêneros alimentícios da AF não poderão ter preços inferiores ao do Programa de Garantia de Preços para a Agricultura Familiar (PGPAF) e deverão ser atualizados semestralmente (BRASIL, 2009b).
} 
articular-se e apresentar um projeto de venda preenchido por uma entidade articuladora. Além disso, os grupos informais precisam apresentar a DAP e o Cadastro de Pessoa Física- CPF de seus componentes. As organizações formais devem apresentar, além do projeto de venda, a DAP Jurídica, o Cadastro Nacional de Pessoa Jurídica- CNPJ, a cópia do estatuto e a cópia de certidões negativas junto ao Instituto Nacional do Seguro Social - INSS, Fundo de Garantia do Tempo de Serviço - FGTS, Receita Federal e dívidas ativas da União.

A seleção dos Projetos de Venda é responsabilidade da comissão criada para esse fim específico, respeitando os critérios de prioridade estabelecidos no Artigo 22 da Resolução $n^{\circ}$ 26/2015. Os agricultores fornecedores selecionados devem assinar um contrato de compra e venda, para a formalização jurídica do processo com as respectivas obrigações e deveres das partes envolvidas. No ato da entrega e recebimento dos produtos, ambas as partes (fornecedor e consumidor entidade executora) devem assinar o Termo de Recebimento, que atesta que os produtos entregues estão de acordo com o Contrato e com os padrões de qualidade e quantidade combinados.

De acordo com o previsto em lei, o pagamento aos fornecedores deve ser feito no prazo de um mês da emissão da nota fiscal ${ }^{9}$. A documentação fiscal e o termo de recebimento serão entregues no setor de pagamento da Entidade Executora ou nas Unidades Executoras (no caso de rede descentralizada). A gestão do PNAE deve ser realizada através do acompanhamento e fiscalização da sociedade, por meio dos CAE's, pelo FNDE, pelo Tribunal de Contas da União - TCU, pela Secretaria Federal de Controle Interno - SFCl e pelo Ministério Público.

A Coordenação Geral do Programa Nacional de Alimentação Escolar- CGPAE- avalia que, somente $73 \%$ dos municípios brasileiros, prestaram contas do recurso recebido do FNDE para a alimentação escolar no ano de 2011 , sendo que $58,4 \%$ destes declararam ter comprado gêneros alimentícios da Agricultura Familiar (aplicação de R\$ 173.061.893,60). No exercício de 2012, apenas 34\% dos municípios registraram a prestação de contas. e destes, $67,2 \%$ declararam que compraram da AF (montante de R\$99.248.638,22).

\footnotetext{
${ }^{9}$ No caso de grupo informal, os agricultores devem emitir individualmente a Nota do produtor rural ou Nota avulsa (cedida pela Prefeitura). O grupo formal apresenta a Nota fiscal da entidade jurídica.
} 
No gráfico abaixo, verificam-se os resultados preliminares apresentados por Saraiva et al. (2013) e pela equipe da CGPAE, mostrando que, ao longo dos anos, em todas as regiões brasileiras, houve aumento do percentual de municípios que compraram produtos da Agricultura Familiar para a alimentação escolar, desde 2010, 2011 até 2012.

Gráfico 1. Percentual de municípios que compraram produtos da Agricultura Familiar para o PNAE em 2010, 2011 e 2012 por região.

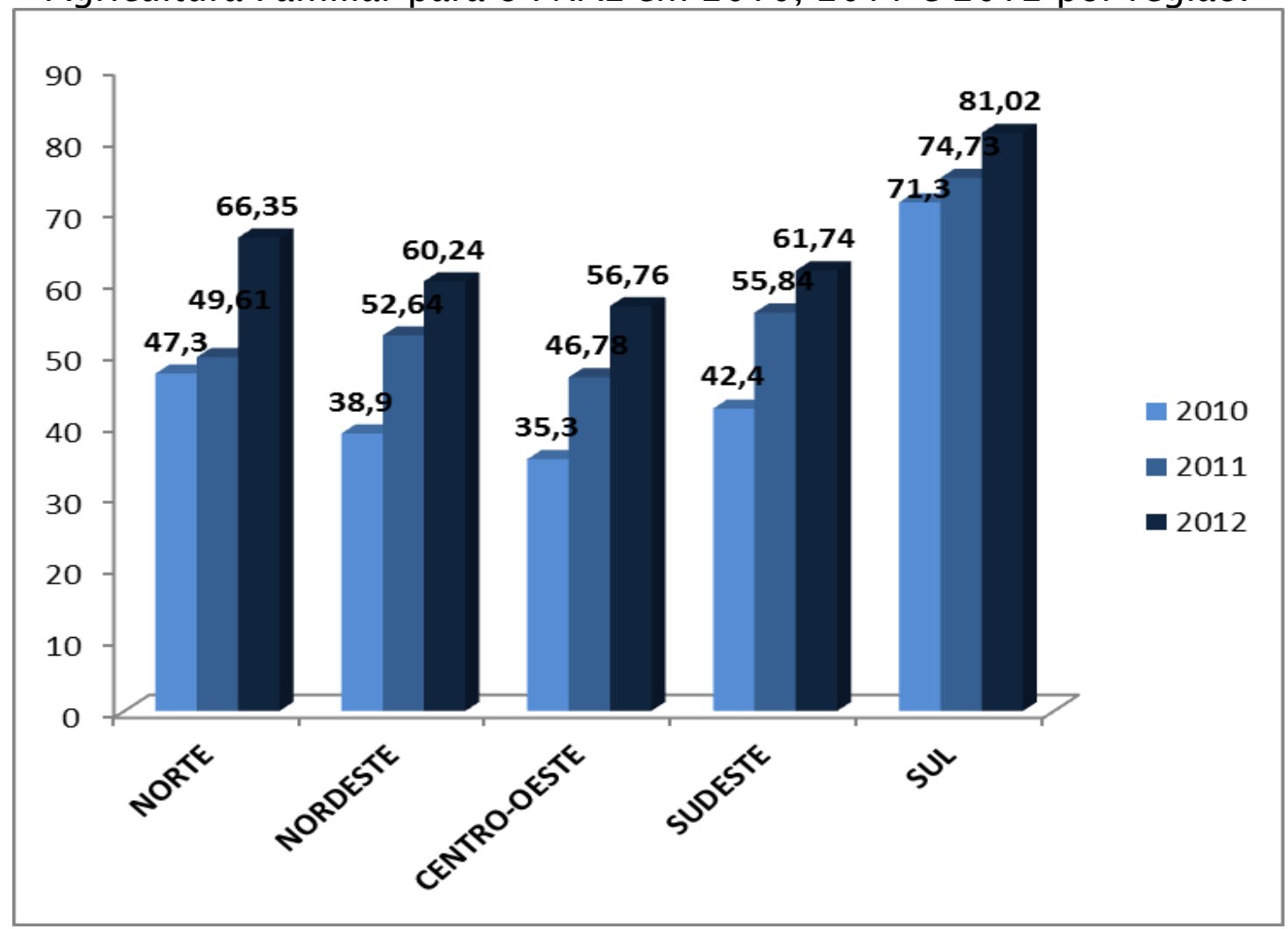

Fonte: Elaborado por Silva (2015) a partir de dados do Sistema de Gestão de Prestação de Contas-SIGPC/FNDE contidos em Saraiva et al. (2013) e Brasil (2013a).

As mudanças no percentual de municípios indicam que, paulatinamente, os gestores públicos estão procurando cumprir a legislação em relação ao PNAE e, consequentemente, essa prática vem influenciando na dinâmica social local. Diante dos resultados encontrados em sua pesquisa, Saraiva et al. (2013) analisam que "como primeiro passo para a compra da AF, deve basear- se em novos referenciais: o de promoção da saúde conjugada à sustentabilidade ambiental, cultural, econômica e social." (SARAIVA et al., 2013, p. 933). 
Face aos dados apresentados pelos autores, observa-se que com a mudança na estrutura de prerrogativas, altera-se a estrutura de poder vigente. Esta política (mercados institucionais) é relativamente nova para as estruturas de Governo, relacionadas à sua implementação, como ministérios, secretarias estaduais e municipais, setores de compras, escolas, empresas de assistência técnica, dentre outros. Também é novidade para os agricultores familiares e suas representações. Como apontam os estudos sobre o PNAE, ainda é necessário avançar na compreensão da legislação que regulamenta o processo de inserção dos produtos da Agricultura Familiar na alimentação escolar em nível local.

\section{O usufruto das prerrogativas do PNAE pelos Agricultores Familiares: oportunidades acessadas e/ou direitos apropriados?}

De modo geral, os agricultores familiares têm fornecido produtos para a alimentação escolar através de distintos arranjos e formas de organização social. Nos municípios de Brasil Novo e Cachoeira do Sul a venda está ocorrendo através da afiliação dos agricultores a grupos formais, seja como sócio ou como fornecedor de produtos aos sócios ou ao grupo. De acordo com os entrevistados, tanto em Brasil Novo quanto em Cachoeira do Sul o percentual de compra tem aumentado a cada ano. Em 2012 percentual de compra de produtos da Agricultura Familiar foi de $27 \%$ em Brasil Novo e $57 \%$ em Cachoeira do Sul. Na Tabela 1 a seguir, são apresentados os valores recebidos do FNDE pelas Prefeituras Municipais de Brasil Novo e de Cachoeira do Sul para aquisição de alimentação escolar no período de 2009 a 2014.

Tabela 1.Valores $(\mathrm{R} \$)$ repassados pelo FNDE às prefeituras municipais de Brasil Novo e Cachoeira do Sul entre 2009 e 2014

\begin{tabular}{ccccccc}
\hline & \multicolumn{5}{c}{ VALOR DE REPASSEDO PNAE À PREFEITURA (R \$ ANO) } \\
\cline { 2 - 7 } MUNICÍPIOS & 2009 & 2010 & 2011 & 2012 & 2013 & 2014 \\
\hline Brasil Novo & $222.283,60$ & $328.560,00$ & $353.220,00$ & $376.224,00$ & $406.564,00$ & $470.540,00$ \\
$\begin{array}{c}\text { Cachoeira } \\
\text { do Sul }\end{array}$ & $289.273,60$ & $433.680,00$ & $443.400,00$ & $505.332,00$ & $624.040,00$ & $672.168,00$ \\
\hline
\end{tabular}

Fonte: Elaborada por Silva (2015) com base nos dados disponíveis em FNDE (2014).

O processo de aquisição de produtos alimentícios produzidos pela Agricultura Familiar destinados à alimentação escolar em Brasil Novo, 
iniciou em 2009 a partir da iniciativa de um técnico extensionista da Empresa de Assistência Técnica e Extensão Rural- EMATER local.

No início de 2014, 77 agricultores associados à APRUCAPEFI estavam diretamente envolvidos no fornecimento de produtos para 0 PAA e para o PNAE. Além da APRUCAPEFI, a AFEBRAN foi reestruturada a partir da articulação ocorrida entre a diretoria da associação e a diretoria do Sindicato dos Trabalhadores e Trabalhadoras Rurais- STTR de Brasil Novo. O objetivo era criar condições para que seus afiliados pudessem acessar os mercados institucionais, reunindo 35 agricultores. Todavia, essa associação forneceu produtos para as escolas municipais apenas durante o ano de 2012.

Em Cachoeira do Sul, as compras de produtos alimentícios da Agricultura Familiar feitas pela Prefeitura para fins da alimentação escolar iniciaram em 2010 e são feitas de agricultores de Cachoeira do Sul e de outros municípios. Naquele ano foram aplicados na compra aproximadamente $11 \%$ do valor repassado pelo FNDE. Segundo os entrevistados, a APRCS começou a ser articulada em 2011 pela diretoria da Associação dos Fruticultores de Cachoeira do Sul- AFRUCA e pela diretoria do Sindicato de Trabalhadores Rurais- STR de Cachoeira do Sul- com a finalidade de mobilizar e organizar os agricultores para comercializarem seus produtos através do PNAE. Atualmente, aproximadamente 70 agricultores familiares associados à APRCS são fornecedores de produtos para as escolas estaduais e municipais. Os demais são vinculados à Cooperativa Agrícola Mista Languiru LTDA e à Cooperativa Agrícola Mista Nova Palma LTDA - CAMNPAL. Nesse município, o percentual de compra de produtos da Agricultura Familiar para as escolas municipais vem aumentando gradativamente, ao longo dos anos. De acordo com a supervisora do Setor de Alimentação Escolar da Secretaria Municipal de Educação - SMED- em 2012, a Prefeitura Municipal aplicou, aproximadamente, 57\% do valor repassado do FNDE à aquisição de produtos da Agricultura Familiar, sendo boa parte desse percentual referente às compras efetuadas nas duas cooperativas.

Em ambos municípios, o processo de organização sócioprodutiva dos agricultores fornecedores foi influenciado por instituições governamentais e não governamentais, com as quais os grupos pesquisados mantêm algum tipo de vínculo. A diversidade de instituições governamentais e não governamentais existentes no 
território propiciou que distintos grupos participassem do processo, uma vez que elas ampliavam as possibilidades de apoio aos agricultores. No Quadro 1 são apresentadas as instituição que tiveram influência direta na articulação das associações no contexto do fornecimento para o PNAE:

Quadro 1. Relação de instituições envolvidas no processo de compra e venda de produtos da agricultura familiar para alimentação escolar de acordo com a associação envolvida.

\begin{tabular}{|c|c|c|}
\hline GRUPOS PESQUISADOS & RELAÇÃO FREQUENTE & RELAÇÃO PONTUAL \\
\hline APRUCAPEFI & PMA $^{1} ;$ PMBN2$^{2}$; EMATER. & $\begin{array}{c}\text { IDEFLOR-Bio }{ }^{7} \text {; SEBRAE8; } \\
\text { Instituto Humaniza; OCB9; } \\
\text { SAGRI10; SPR }{ }^{11} \text {; PDRS- } \\
\text { XINGU12 }\end{array}$ \\
\hline AFEBRAN & STTR; COPOXIN3 3 IPAM 4 . & PMBN; EMATER; SAGRI. \\
\hline APRCS & $\begin{array}{l}\text { STR; AFRUCA; EMATER; } \\
\text { PMCS5; ESCOLAS DO } \\
\text { ESTADO; COMAGRO } 6\end{array}$ & $\begin{array}{c}24^{\mathrm{a}} \mathrm{CRE}^{13} \text {; CODETER }{ }^{14} \\
\text { Território Central do RS; } \\
\text { SDR }{ }^{15} \text {. }\end{array}$ \\
\hline
\end{tabular}

Fonte: Pesquisa de campo (2014).

Notas: 'Prefeitura Municipal de Altamira; ${ }^{2}$ Prefeitura Municipal de Cachoeira do Sul; ${ }^{3}$ Cooperativa dos Produtores Orgânicos do Xingu; ${ }^{4}$ Instituto de Pesquisa da Amazônia; 5Prefeitura Municipal de Brasil Novo; ${ }^{6}$ Conselho Municipal de Desenvolvimento Agropecuário; 7 Instituto de Desenvolvimento Florestal e da Biodiversidade do Estado do Pará; ${ }^{8 S e r v i c ̧ o ~ B r a s i l e i r o ~ d e ~ A p o i o ~ a ̀ s ~ M i c r o ~ e ~ P e q u e n a s ~ E m p r e s a s ; ~}{ }^{9}$ Organização das Cooperativas Brasileiras; 10 Secretaria Estadual de Agricultura; 11 Sindicato dos Produtores Rurais; 12 Plano de Desenvolvimento Rural Sustentável do Xingu; 13 Coordenadoria Regional de Educação; ${ }^{14}$ Conselho de Desenvolvimento Territorial; 15 Secretaria Estadual de Desenvolvimento Rural.

Tanto em Brasil Novo quanto em Cachoeira do Sul, a construção de uma rede de atores foi fundamentais na estruturação do grupo formal e do processo de venda. Os grupos que mais cresceram como fornecedores foram são os que mantêm relações com o maior número de instituições, destacando-se as estabelecidas com gestores públicos e extensionistas.

A APRUCAPEFI tinha relações mais frequentes com os agentes das prefeituras e com os técnicos da EMATER. As relações com as prefeituras ora eram de natureza mercantil ora como de assessoria e assistência técnica. Com as demais instituições, as relações eram ocasionais, para tratar questões de assistência técnica e/ou liberação de recursos a fundo perdido. 
A AFEBRAN mantinha relações mais frequentes com o STTR, como entidade articuladora e que disponibilizava alguma infra-estruturar para demandas específicas, como o trator. Com a COPOXIN o vínculo facilitava o uso do caminhão. Todos os sócios da AFEBRAN são afiliados ao STTR e, muitos deles, também são associados à COPOXIN, o que favoreceu a aproximação entre as entidades e os sócios. A relação com os técnicos da EMATER, e outros gestores públicos, era pontual, em casos de assessoria técnica na emissão da DAP e da relação mercantil.

Os membros da APRCS relacionavam-se de forma mais frequente com os consumidores- Prefeitura e escolas estaduais, com os diretores e técnicos do STR, com os diretores da AFRUCA, com o extensionista da EMATER e com os conselheiros do COMAGRO. Enquanto a relação entre Associação e EMATER é constituída através da prestação de serviço de assessoria técnica, a participação dos representantes do STR no COMAGRO tem sido de utilidade para ampliar o poder de barganha do grupo de Cachoeira do Sul junto à Prefeitura. Assim como no caso da AFEBRAN e da ASCOSAN, o vínculo dessa associação é mais forte com o STR e com a AFRUCA pois, os membros do grupo já eram afiliados a esse sindicato anteriormente à criação da associação fornecedoras de produtos através do PNAE. Em ambos os municípios, os diretores do STTR e do STR, além de prestar assessoria na articulação com os gestores públicos, têm influenciado na organização social do grupo e na administração da associação, tornando-se um referente importante para contatos e informações, tanto para os gestores como para os agricultores.

Além dos vínculos institucionais, outro importante efeito na organização social são os laços estabelecidos entre os agricultores por ocasião da possibilidade de venda para os programas estatais de aquisição de alimentos. Resultado semelhante foi encontrado por Diniz (2014). Segundo analisado pela autora,

os vínculos sociais estabelecidos foram fortalecidos após a inserção no PNAE. Sendo estes vínculos concernentes tanto ao interesse de novos indivíduos de se associarem para participarem dos projetos anuais da alimentação escolar, quanto da própria Rede Ecovida [...] (DINIZ, 2014, p. 92).

Tanto em Cachoeira do Sul quanto em Brasil Novo, o apoio e a atuação dos gestores vinculados às Secretarias de Agricultura e de 
Educação nos municípios, por exemplo, estão relacionados a relações de proximidade entre lideranças e gestores, lideranças e lideranças, gestores e gestores.

Todos os grupos contaram com assessoria direcionada à documentação de regularização da associação e dos instrumentos operacionais da compra e da venda, ora direcionada à organização da produção agrícola no plano individual e coletivo. A assessoria foi fundamental para coesão do grupo e entendimento dos caminhos a serem seguidos até o mercado institucional. Todavia, a constituição do grupo que reativou a APRUCAPEFI foi, de certo modo, pautada na personificação da política pública através do extensionista e da liderança, da ação dos agentes estatais e da condição de ser membro do grupo.

A agregação dos agricultores aos grupos foi ocorrendo paulatinamente conforme as ações das lideranças tornavam concretas a elaboração do projeto de venda e a submissão deste à CONAB, ou aos editais de Chamada Pública. Nesse início de processo, a construção foi coletiva derivada do interesse mútuo de agricultores, parceiros e gestores em acessar a oportunidade. A divisão de tarefas agilizou a mobilização das informações necessárias e das pessoas. As relações de conhecimento facilitaram a negociação e a obtenção de apoio estrutural para que os agricultores pudessem cumprir o contrato.

Por outro lado, principalmente na situação estudada no Pará, a confiança em sistemas peritos favoreceu o desencaixe de relações de confiabilidade entre os atores leigos (GIDDENS, 1991). Os sistemas de peritos ao estarem associados à relação clientelista estabelecida entre lideranças e fornecedores, e entre lideranças e fornecedores em relação aos gestores públicos, corroboraram com a reprodução de relações de dominação entre os atores, ampliando a dependência de uns em relação a outros. Nesse sentido, as ações dos governantes são estruturantes do processo, mas podem remeter à condição de apadrinhamento dos investimentos, o que fragiliza a consolidação de ações coletivas contínuas e duradouras.

Considerando esses aspectos, as experiências estudadas mostram que o processo de apropriação das prerrogativas dispostas no PNAE ainda é incipiente. De certo modo, a apropriação da prerrogativa é fragilizada ao passo que a reinterpretação do direito à venda a converte 
em possibilidade, não em certeza. O fato de entregar para a merenda não expressa necessariamente a compreensão de fornecedores e gestores públicos de que a venda constitui-se um direito. Para alguns fornecedores a venda para o Estado é compreendida como oportunidade de comercializar o produto e aumentar a renda e como possibilidade por ser dependente da ação de outros agentes, como o gestor público ou o presidente da associação. Quando o direito é reconhecido, atribuise às lideranças- e não ao Estado- a oportunidade de venda. Muitas vezes, a abertura comercial garantida em Lei é associada ao poder de barganha da liderança e à boa vontade do gestor público.

Desta forma, as ações dos atores na criação e no usufruto de oportunidades sociais derivam das interpretações feitas pelos envolvidos diretamente no processo acerca dos efeitos que a compra de produtos da AF - e dos grupos interessados - têm nos elementos estruturantes do sistema social (nas estruturas de prerrogativas e de provimentos): orientação técnica, recursos, financiamentos, informação, infraestrutura, dentre outros.

Conforme exposto no Quadro 2 a seguir, a partir das experiências dos agricultores, individuais e coletivas, infere-se que há diferenças entre vender para Estado através do PNAE e se apropriar do direito de fornecer os produtos. 
Quadro 2. Diferenças entre inserção no mercado da alimentação escolar e apropriação do direito à venda

\begin{tabular}{|c|c|}
\hline VENDER PARA O PNAE & APROPRIAÇÃO DO DIREITO À VENDA \\
\hline $\begin{array}{l}\text { a) Informação menos completa sobre a } \\
\text { possibilidade da venda: } \\
\text { - Busca de informações sobre como fazer } \\
\text { para vender para a alimentação escolar, seja } \\
\text { como fornecedor direto ou indireto; } \\
\text { - Articulação com pessoas que possam } \\
\text { informar sobre como vender. }\end{array}$ & $\begin{array}{l}\text { a) Informação mais completa sobre a } \\
\text { obrigatoriedade da compra pelos governos } \\
\text { municipais e estaduais: } \\
\text { - Busca de informações sobre os } \\
\text { procedimentos burocráticos da venda; } \\
\text { - Articulação com pessoas que contribuam } \\
\text { na compreensão da legislação. }\end{array}$ \\
\hline b) Afiliação à associação ou não. & $\begin{array}{l}\text { b) Afiliação a um grupo formal ou informal } \\
\text { ou opta pela venda individual. }\end{array}$ \\
\hline $\begin{array}{l}\text { c) Informação sobre a demanda (produtos } \\
\text { solicitados pelos gestores públicos). }\end{array}$ & $\begin{array}{l}\text { c) Participa da construção do cardápio, } \\
\text { influenciando na adição de produtos. }\end{array}$ \\
\hline $\begin{array}{l}\text { d) Recebe informação sobre a publicação da } \\
\text { Chamada Pública. }\end{array}$ & $\begin{array}{l}\text { d) Participa da elaboração da Chamada } \\
\text { Pública, influenciando na adição dos } \\
\text { produtos a serem solicitados. }\end{array}$ \\
\hline $\begin{array}{l}\text { e) Organização da produção agrícola } \\
\text { - Mensuração de quantidade e variedade de } \\
\text { produtos a serem vendidos; } \\
\text { - Investimentos ou não na produção agrícola } \\
\text { (aumento de área plantada e/ou insumos); } \\
\text { - Reorganização do trabalho. }\end{array}$ & $\begin{array}{l}\text { e) Organização da produção agrícola } \\
\text { - Mensuração de quantidade e variedade de } \\
\text { produtos a serem vendidos; } \\
\text { - Investimentos ou não na produção agrícola } \\
\text { (aumento de área plantada e/ou insumos); } \\
\text { - Reorganização do trabalho. }\end{array}$ \\
\hline $\begin{array}{l}\text { f) Sabe ou não da elaboração do projeto de } \\
\text { venda, mas não participa da elaboração. }\end{array}$ & $\begin{array}{l}\text { f) Participa da elaboração do projeto de } \\
\text { venda. }\end{array}$ \\
\hline $\begin{array}{l}\text { g) Informa o preço de venda do produto, } \\
\text { independente do preço de referência. }\end{array}$ & $\begin{array}{l}\text { g) Participa do debate sobre o preço dos } \\
\text { produtos, tomando como base o preço de } \\
\text { referência. }\end{array}$ \\
\hline $\begin{array}{l}\text { h) Não sabe os critérios para seleção dos } \\
\text { projetos: } \\
\text { - A seleção do projeto/produtos é feita a } \\
\text { partir do menor preço. }\end{array}$ & $\begin{array}{l}\text { h) Cobra que a seleção do projeto/produtos } \\
\text { seja feita seguindo os critérios dispostos na } \\
\text { Lei. }\end{array}$ \\
\hline $\begin{array}{l}\text { i) Não participa das negociações sobre a } \\
\text { organização da logística de entrega. }\end{array}$ & $\begin{array}{l}\text { i) Participa nas negociações sobre a } \\
\text { organização da logística de entrega. }\end{array}$ \\
\hline j) Recebe do pagamento. & j) Recebe o pagamento. \\
\hline k) Aguarda nova negociação. & k) Organiza nova negociação. \\
\hline $\begin{array}{l}\text { I) Racionalidade do agricultor: } \\
\text { - alternativa de venda da produção ou novo } \\
\text { mercado de venda. Agente econômico que } \\
\text { amplia os canais de comercialização. }\end{array}$ & $\begin{array}{l}\text { I) Racionalidade do agricultor: } \\
\text { - busca o mercado garantido por lei. Exercer } \\
\text { um direito como cidadão. }\end{array}$ \\
\hline
\end{tabular}

Fonte: Elaborado por Silva (2015).

As distinções entre acessar ao recurso da política e se apropriar da prerrogativa, são demarcadas ao longo do processo de venda dos produtos. Segundo mostra o Quadro 2, o acesso aos recursos da política pública PNAE por parte dos agricultores familiares não significa, 
necessariamente, a apropriação das prerrogativas dispostas na Lei. A apropriação da prerrogativa (direito à venda para o Estado) ocorre quando os atores envolvidos têm clareza sobre o seu papel no processo e quando dispõem de informação sobre a operacionalização do processo; apresentam interesse (expectativa) em fornecer; têm poder de decisão e oportunidades (condições estruturais, físicas e sociais) que viabilizem o fornecimento; entendem e deliberam sobre a posição social ocupada nas relações de dominação.

A não apropriação das prerrogativas ocorre em situações nas quais se usufrui do PNAE enquanto um canal de venda disponível para seus produtos, sem que haja a compreensão da venda enquanto prerrogativa, tampouco apreensão dos procedimentos burocráticos. Nesse sentido, o fornecimento de produtos alimentícios para a alimentação escolar não é necessariamente reflexo do reconhecimento, por parte dos agricultores, da prerrogativa disposta na Lei 11.947/2009. Nessa situação, os agricultores são atores leigos (GIDDENS, 1991), por serem constrangidos por estruturas sociais derivadas das disputas político-partidárias presentes na gestão municipal, sindical e associativa. A condição de leigo não expressa, necessariamente, incapacidade de compreensão da existência dessa estrutura constrangedora. Ao contrário, os agricultores reconhecem a estrutura de dominação que é conformada a partir das relações estabelecidas entre afiliados políticos e se reconhecem nesse contexto.

Ao longo do processo de operacionalização do Artigo 14 da Lei $\mathrm{n}^{\circ}$ $11.947 / 2009$, as redes de contato, sejam através de relações profissionais, de amizade ou de parentesco, foram fundamentais na geração e no usufruto das oportunidades geradas a partir da possibilidade de venda de produtos para o Estado, como tornar-se fornecedor, acessar serviço de extensão rural, obter DAP, associar-se a entidades representativas, dentre outras. Tais oportunidades em nível local tornam-se personificadas, tanto para quem será o público beneficiário, para os parceiros ou para os gestores públicos. A personificação da oportunidade gerada, bem como os meios de acesso para seu usufruto aparece como atributo do processo de apropriação das políticas públicas. Em vista disso, a rede interpessoal da qual fazem parte os agricultores configura-se como importante provimento que 
possibilitou o acesso dos mesmos às políticas de fornecimento de produtos para o Estado.

As relações sociais são elementos estruturantes da operacionalização da política pública, tanto no sentido das ações dos gestores públicos, quanto de sua apropriação e usufruto pelos beneficiários. Nesse contexto, conhecimento [conhecer pessoas], parentesco e amizade são ainda as ligaduras que permitiram que a rede fosse acionada. Na interpretação de Long e Ploeg (2011), as relações sociais favorecem as conexões entre os diferentes atores, gerando uma rede que favorece práticas conjuntas. Afirmam os autores que:

a capacidade de agente (e poder) depende crucialmente da emergência de uma rede de atores que se tornam parcialmente, embora quase nunca completamente, envolvidos nos projetos e práticas de outro indivíduo ou indivíduos. Por conseguinte, o agente efetivo requer a geração/manipulação estratégica de uma rede de relações sociais e canalização de itens específicos (como reivindicações, ordens, bens, instrumentos e informação) através de certos pontos fundamentais de interação (LONG; PLOEG, 2011 , p. 8).

A aquisição de produtos da Agricultura Familiar para a alimentação escolar está conectada à atuação das pessoas e de suas relações, seja para favorecer ou para constranger. O processo pode ser considerado uma engrenagem na qual os atores envolvidos são peças e seu funcionamento está correlacionado ao encaixe e desencaixe das relações sociais estabelecidas entre eles. Quando a ação de um ator não acompanha a ação do outro, geram-se os desencaixes. Em algumas situações, a agência está suprimida pela subordinação à qual os agricultores (fornecedores diretos ou não) estão submetidos. A subordinação, derivada da dominação exercida por outros atores sobre si, torna-se um elemento que constrange a atuação dos agricultores no processo. Lembra Dubet (1994) que os atores agem limitados por constrangimentos das mais diversas origens e dimensões, estando sua agência associada, também,à representação que o ator tem de si e do sistema de dominação do qual faz parte.

A relação clientelista, que por vezes parece reger a mobilização de agricultores fornecedores, demonstra que há a possibilidade de agência, mas não há agência de fato. Segundo Dubet (1994), os atores fazem 
suas escolhas conforme as oportunidades às quais tem acesso. A agência revela-se nas estratégias para usufruir da oportunidade, sendo influenciada por interesses pessoais, que são alcançados através do coletivo. O grupo, através de estratégias de ação, reproduz relações de dominação e clientelismo.

Nas situações observadas, agricultores e representantes da Agricultura Familiar questionam o comportamento dos gestores, visando romper as barreiras políticas que impedem o usufruto de seus direitos. Articulam-se com como funcionários públicos municipais, técnicos de instituições parceiras, conselheiros, promovendo ações que interferem no processo de compra e venda, de modo a ampliar as oportunidades de acesso ao PAA e/ou ao PNAE. O usufruto do direito à venda ou a perspectiva futura de acessar o recurso da política pública representam a apropriação da prerrogativa constituída.

A apropriação fica limitada, tornando-se parcial ou incompleta, quando os atores não questionam a Lei e não buscam aprofundar seu entendimento através de sua própria leitura e do debate coletivo, visando esmiuçar o que está disposto em cada artigo e resolução que orienta a venda. O conhecimento do funcionamento burocrático das etapas do processo é atribuído a outros agentes cuja posição social está associada à existência de conhecimento perito, tal como os técnicos que os assessoram, e as lideranças que não são membros do grupo formal. Considera-se que em algumas situações $o$ indivíduo exerce sua condição de agente ao decidir não apropriar-se. Todavia, com frequência, ocorre a sonegação de informações pelos agentes que ocupam a posição de dominadores e a desqualificação da prerrogativa enquanto direito.

Considerando esses aspectos, nas situações de muitos fornecedores, a inserção no mercado da alimentação escolar não reflete, a priori, o exercício pleno da cidadania. Quando as prerrogativas não são apropriadas, a cidadania fica fragilizada principalmente quando é relegada a outrem. Na perspectiva de Santos (1995), ser cidadão é ter consciência do lugar que se ocupa na sociedade e lutar para mudar ou permanecer nele, na posição social e no papel que cumpre.

As prerrogativas, tal como são formuladas, e as normas que orientam seu usufruto, exigem o cumprimento de regras burocráticas. 
Muitas vezes o Estado não dispõe, ou não viabiliza as possibilidades de escolhas dos potenciais beneficiários.

\section{O PNAE como provimento de cidadania}

As compras de gêneros alimentícios da agricultura familiar pelo Estado constituem oportunidades para a comercialização, cumprindo os objetivos de melhorar a qualidade da alimentação escolar e de agregar renda aos agricultores fornecedores. Essa política caracteriza-se como atributo de provimento, uma vez que o fornecimento de produtos para a alimentação escolar é compreendido como possibilidade de melhoria de vida ao ampliar as chances de vida dos agricultores. A venda através dos programas governamentais, PNAE ou PAA, é um meio para aumentar a receita familiar, para obter o reconhecimento como agricultor que trabalha - e que produz alimento -, para participar da associação, das negociações políticas, entre outras atividades. Enquanto meio, e não enquanto fim, a prerrogativa instituída através da lei, torna-se provimento do exercício da cidadania.

A condição de cidadão pode constituir-se de forma controversa, em um contexto no qual o usufruto da prerrogativa ocorre em situações de coalizões e disputas. A cidadania, frequentemente, é fragilizada ou consolidada nas relações políticas e econômicas entre indivíduoEstado, indivíduo-sociedade e sociedade-Estado. Segundo Ghizelini (2010, p. 173), é importante considerar que:

[...] para que estes agricultores sejam considerados atores, necessário se faz extrapolar a dimensão político-institucional, pois o reconhecimento dos agricultores enquanto atores deve estar articulado ao reconhecimento social e econômicos por parte da sociedade em que estes se inscrevem (GHIZELINI, 2010, p. 173).

Em sociedades democráticas, as coalizões e as disputas entre grupos promovem a reorganização das estruturas de prerrogativas e de provimentos ao passo em que há participação dos atores nas arenas de negociação. É nesse contexto que a cidadania é objetivada a partir da agência. A disponibilidade de prerrogativas e de provimentos é 
conquistada através da reivindicação daqueles não contemplados no acesso ao recurso da política pública.

Nas situações analisadas, a (re)distribuição do recurso da política está conectada à participação dos diferentes grupos na concorrência do PNAE. Retoricamente, todos os agricultores familiares têm o direito de participar do processo, no entanto, nem todos dispõem dos mesmos provimentos. Em vista disso, ao avaliar-se os impactos e a eficácia da implementação de políticas públicas, torna-se fundamental enfatizar sua vinculação com as demais políticas a fim de se identificar as condições estruturais que constrangem ou favorecem sua operacionalização.

Também é importante considerar que, a mudança de posição dos atores na estrutura de acesso aos privilégios, submete alguns a privações, gerando conflitos em termos de decisões sobre a distribuição de benefícios. Na situação dos grupos estudados nessa pesquisa, as disputas em torno do PNAE são manifestações de grupos de conflitos pré-existentes, que mobilizam diversas estratégias para seguir no jogo, cujas conquistas são os recursos das políticas públicas e o poder político.

Em Brasil Novo, embora as disputas partidárias em torno do recurso da política pública e da posição de fornecedor gerem incômodo nos interessados em fornecer para os programas estatais de aquisição de alimentos, a opção pelo não embate direto parece exprimir a compreensão - e até certo 'respeito' - dos privilégios legitimados aos agricultores/grupos afiliados ao grupo político que ocupa cargos públicos (representativos do poder do Estado), em detrimento do outro considerado como oposição, funcionando como meio social de regulação dos conflitos. Nesse local, está institucionalizado, como 'regra do jogo', que a conquista de benefício individual e coletivo ocorre concomitante à conquista do cargo público, o que transfere a disputa para outro plano, o eleitoral-partidário.

Em Cachoeira do Sul os conflitos são de outra ordem, pois, a gestão pública municipal e a entidade articuladora fazem parte do mesmo grupo político o que parece dirimir a existência de disputas partidárias. Até o término da pesquisa, não havia no município outra associação para concorrer com a APRCS. Os envolvidos no processo de compra e venda e na articulação dos atores incentivam os agricultores 
interessados a transformar-se em fornecedores e afiliarem-se à associação fornecedora, o que dificulta a emergência de novos grupos formais e diminui a possibilidade de disputas intracategoria. A concorrência ocorre entre duas categorias (comerciantes e agricultores familiares), ocorrendo pressão dos representantes da Agricultura Familiar sobre os gestores que elaboram o cardápio e que organizam o processo licitatório e de chamada pública, com vistas à ampliação do número de produtos e da quantidade demandada. Desta forma, os conflitos entre gestores e fornecedores são fruto das divergências e disputas em relação aos produtos demandados via Licitação e via Chamada Pública.

As negociações entre os grupos e os gestores e entre agricultores são meios para regular os $\operatorname{conflitos}^{10}$. A regulamentação tem ocorrido através da definição de normas que codificam e organizam o comportamento dos grupos entre si e intra-grupo. A lei é a forma de democratizar o acesso a recursos de políticas públicas, disponibilizados pelos gestores públicos através da demanda da compra. O usufruto das opções depende das condições estruturais para o entendimento da demanda e isso inclui a capacidade de mobilização, negociação e de apropriação dos procedimentos burocráticos.

Segundo a perspectiva weberiana, a burocracia funciona a partir de regras que 'neutralizam' a personificação e a pessoalidade na distribuição de recursos e o funcionamento da administração pública e das grandes empresas. A demanda dos gestores (produtos a ser comprados) no processo de compra estatal é pública, aberta e concorre quem atende os critérios pré-estabelecidos e quem tem produtos a ofertar. Nas situações estudadas, no entanto, a burocratização do processo e as novas normativas de regulação do fornecimento não extinguiram as relações interpessoais, coalizões e disputas. Ao contrário, as relações pessoais 'desneutralizam' a gestão da aquisição

\footnotetext{
10 A análise de Dahrendorf $(1981,1992)$ sobre os conflitos sociais, mesmo que macrossociológica corrobora com o entendimento de que a regulamentação é importante fator para minimizar métodos violentos de embates e repressão dos grupos dominantes em relação aos grupos de oposição. Para esse autor, os conflitos sociais expressam os antagonismos que vão surgindo nas estruturas sociais, podendo ser dirimidos, mas não solucionados definitivamente.
} 
estatal de produtos da Agricultura Familiar, tanto em nível de grupo quanto na administração pública.

O acesso aos recursos da política pública, circunscrita como prerrogativa, ocorre de diversas formas, nem todas convergentes com as normativas estabelecidas na legislação e pelos agentes do Estado. Todavia, independente dos caminhos percorridos para seu usufruto, a oportunidade de ingresso está conectada a um conjunto de prerrogativas que, quando acessadas, oferecem condições para se usufruir da política em foco.

Uma política, seja na sua construção ou na sua operacionalização, não deve ser analisada de forma unilateral ou individualizada, uma vez que seu usufruto pode requerer a conexão entre diversas políticas que, nessa situação assumem a posição de prerrogativas assessórias. No caso do PNAE e do PAA, políticas como o PRONAF e os programas de ATER, por vezes, ilustram tais prerrogativas. Como afirmado por Sen (1982, 2001) e ressaltado por Dahrendorf (1992), a falha em uma das prerrogativas do conjunto pode obstruir a mobilização de outras.

No acesso a recursos de políticas públicas, os arranjos entre prerrogativas e provimentos podem ser diversos, de acordo com o contexto local e com os meandros das ações estatais estaduais e federais. São as ligaduras que dão forma e sustentação a eles. As ligaduras concernentes à combinação entre prerrogativas e provimentos são acionadas e modificadas conforme a possibilidade e interesse em usufruir o direito conquistado. Uma política pública, enquanto prerrogativa, não é acessada de forma isolada, nem pode ser considerada estática. Uma determinada política pode ser considerada prerrogativa, ora pode ser provimento, conforme sua função na teia que possibilita o usufruto do direito requerido:

os provimentos são chances de vida muito imperfeitas sem as prerrogativas, e as chances de vida também incluem aquele elemento menos tangível, as ligaduras. Mesmo assim são chances, e nossas vidas são o que fazemos a partir delas. A vida diz respeito à atividade e sentido, para quais tanto a cidadania quanto a riqueza das nações são meramente uma condição (DAHRENDORF, 1992, p. 199).

As chances de vida resultam da subtração entre oportunidades e privações e são constituídas a partir da conexão entre prerrogativas e 
provimentos. Nas situações estudadas, as oportunidades sociais são asseguradas pelas estruturas sociais. Esses laços são tecidos a partir de diversas relações sociais estabelecidas entre os atores, tais como relações políticas, de amizade, de parentesco, dentre outras que os vinculam. No acesso ou não dos agricultores familiares ao mercado da alimentação escolar o status, o prestígio e as relações sociais se mostram como provimentos que possibilitam ampliação das oportunidades dos indivíduos.

Em Cachoeira do Sul, a mobilização dos fornecedores, inicialmente, pautou-se na estratégia de reunir agricultores "conhecidos" (que faziam parte da mesma rede-profissional/associativa ou de parentesco) para facilitar a organização do grupo. À medida que a associação foi sendo estruturada, buscou-se ampliar o número de sócios, vinculados às redes às quais estavam vinculados os sócios antigos, expressando a importância das relações sociais na construção do processo de venda. Em Brasil Novo, na situação das associações concorrentes, as prerrogativas e os provimentos que facilitaram ou que constrangeram o acesso ao recurso do PNAE são conectados através de ligaduras que conformam a dinâmica social local, tais como relações clientelistas, de parentesco, de amizade e de reciprocidade (troca de favores).

A inserção dos agricultores familiares no mercado institucional não significa necessariamente a conquista do direito ao recurso da política pública. Os mercados institucionais, legalizados como novas prerrogativas para a agricultura familiar, desestruturaram 0 corporativismo legitimado através do modelo convencional de compras públicas (processo licitatório). No entanto, não modificou o modelo corporativo com o qual são operacionalizadas as ações estatais. Historicamente, a desigualdade ao acesso ao recurso da política pública, essas prerrogativas privilegiam um determinado segmento da sociedade em detrimento de outros que até então gozavam das regalias despendidas na lei. Por estar vinculado a essa categoria social, há modificação em termos de atores privilegiados.

A distribuição de recursos previstos no orçamento da União e no sentido do reconhecimento da importância da agricultura familiar perante a sociedade brasileira, os programas estatais de aquisição de alimentos são instrumentos da construção da cidadania dessa categoria 
social. Considerando o aspecto econômico da cidadania, em nível micro, no âmbito das unidades de produção familiar dos fornecedores de produtos, a condição de cidadão pode ser observada através das mudanças nos sistemas técnicos e na gestão das atividades produtivas. Tais mudanças, frutos da ampliação da renda derivada da venda para o PNAE e/ou para o PAA e/ou de programas de fomento, têm refletido na participação mais efetiva de mulheres e jovens no planejamento e execução das atividades agrícolas.

O interesse na venda para o PNAE fomentou a participação política dos agricultores e a organização coletiva em prol de benefícios para a categoria social. As características sociais e econômicas locais contribuem para que seja rediscutida a regulamentação do acesso do direito conquistado de modo a dirimir os descompassos entre a organização produtiva e social em nível local e a organização social e produtiva requerida na implementação da política pública. Apesar de não romper com as ligaduras que conectam prerrogativas e provimentos, a possibilidade de venda para o Estado, paulatinamente, tem fomentado o empoderamento dos agricultores familiares frente às relações de subordinação.

As mudanças políticas têm causado, mesmo que timidamente, mudanças sociais para além da geração de renda. Os programas estatais de aquisição de alimentos estão conseguindo aliar o desenvolvimento econômico e cidadania, questão posta por Dahrendorf (1992) como fundamental para que países pobres ou em desenvolvimento possam superar as privações pelas quais passa boa parte de sua população.

Apesar dos avanços ocorridos na democratização do acesso aos recursos públicos, e de valorização de categorias sociais recémreconhecidas positivamente como conformadoras da sociedade brasileira, ainda há barreiras que vedam a plena apropriação dos direitos conquistados e, consequentemente, o exercício da cidadania. Tanto em relação às prerrogativas quanto de provimentos, àqueles que estão mais bem articulados, com os que detêm o poder no âmbito dos órgãos públicos e das instituições parceiras, demonstram que as relações sociais estão no cerne do acesso dos grupos sociais aos recursos das políticas públicas. Nessa perspectiva, a cidadania constituída através dos programas estatais mostra-se fragilizada por estar à mercê da vontade política dos gestores públicos e das lideranças 
que mediam a organização sócio-produtiva que viabiliza a venda de produtos através dos programas públicos.

Por outro lado, a operacionalização da lei requer o investimento tanto dos gestores públicos, das entidades parceiras e dos agricultores familiares na compreensão e discussão sobre vários temas, como organização dos agricultores, organização da produção, implantação de agroindústrias, legislação sanitária e legislação ambiental. A implementação de normas, legalmente constituídas, 'força' os atores envolvidos a problematizarem tais temáticas no âmbito de suas ações, o que a torna importante elemento para discutir o Desenvolvimento Rural. 


\section{Considerações finais}

Os resultados do trabalho realizado permitem concluir que, o percurso dos agricultores familiares em busca do acesso à política de fornecimento de produtos para a alimentação escolar, têm sido percorrido de acordo com o grupo ao qual estão afiliados, com os atores envolvidos no processo e com a conjuntura política do município. As estratégias dos agricultores para obter o direito de vender seus produtos para os gestores públicos através do PNAE estão relacionadas ao processo de construção da demanda de produtos a ser por eles atendida. Nesse sentido, o cardápio é o instrumento que dá objetividade e materialidade à demanda dos gestores públicos e, consequentemente, à possibilidade de fornecimento ao Estado, sendo o processo de elaboração do mesmo crucial na conexão entre agricultura familiar e alimentação escolar.

O estudo mostra que a participação dos agricultores familiares no PNAE não pode ser considerada apenas no contexto da geração de renda, uma vez que a aquisição de produtos não está relacionada apenas ao mercado. O reconhecimento social dos mesmos como produtores de alimentos, a apropriação da prerrogativa e as mudanças nas estruturas de oportunidades também são elementos importantes. Vale ressaltar que o reconhecimento social dos agricultores familiares como participantes da sociedade (cidadãos), seja como produtores de alimentos ou como pessoas com direito ao acesso aos recursos de políticas públicas, expressa mudanças nas estruturas de oportunidades. Como o direito à venda de produtos ao Estado é condicionado pela demanda do consumidor (nesse caso o Estado através do gestor público), as exigências dos gestores públicos, enquanto consumidores dos produtos a serem adquiridos, são um importante elemento na operacionalização do programa. Associadas a esse elemento estão a organização social, desprendida no processo de venda (ou de pretensão de venda), e as relações sociais estabelecidas pelos indivíduos, tendo em vista que o acesso às informações e a organização das atividades produtivas não estão dissociadas da interação entre indivíduos ou grupos.

Com a aprovação da Lei $n^{\circ} 11.947 / 2009$, os agricultores familiares ganharam nova posição (mais vantajosa) em relação à 
condição de cidadão. As prerrogativas dispostas na referida lei transpassam barreiras historicamente constituídas, como a Lei de Licitações. Por outro lado, o cumprimento ou não do Artigo $n^{\circ} 14$ da Lei $n^{0} 11.947 / 2009$ e das resoluções regulamentadoras por parte dos gestores públicos e dos agricultores familiares, está relacionado às características da produção agrícola nos municípios, à dinâmica político-partidária nas instâncias municipal, estadual e federal, às relações pessoais que configuram a conformação dos grupos. Em vista disso é preciso analisar se novas barreiras de privilégios foram construídas com a nova lei, e se as privações decorrentes das antigas estruturas de prerrogativas foram superadas, de modo a identificar o que da estrutura de prerrogativas foi superado, reformulado e mantido.

\section{REFERÊNCIAS}

AGNE, C. L. Mudanças institucionais na agricultura familiar. as políticas locais e as políticas públicas nas trajetórias das famílias nas atividades de processamento de alimentos no Rio Grande Do Sul. 2014. 260f. Tese (Doutorado em Desenvolvimento Rural) - Programa de Pós-Graduação em Desenvolvimento Rural, Universidade Federal do Rio Grande do Sul, Porto Alegre, 2014.

BACCARIN, J. G. et al. Agricultura familiar e alimentação escolar sob a vigência da Lei 11.947/2009: adequação das chamadas públicas e disponibilidade de produtos no estado de São Paulo em 2011. In: CONGRESSO DA SOCIEDADE BRASILEIRA DE ECONOMIA, ADMINISTRAÇÃO E SOCIOLOGIA RURAL, 50., 2012, Vitória. Anais... SOBER: Vitória, 2012.

BELIK, W. A política brasileira de segurança alimentar e nutricional: concepção e resultados. Revista Segurança Alimentar e Nutricional, Campinas, v. 19, n. 2, p. 94-110, jul./ago. 2012.

BRASIL. Lei $n^{\circ}$ 11.947, de 16 de junho de 2009. Dispõe sobre o atendimento da alimentação escolar e dá outras providências. Brasília, 2009a. 
<http://www.planalto.gov.br/ccivil_03/_ato20072010/2009/lei/l1 1947.htm>. Acessado em: 10 fev. 2013.

BRASIL. Resolução $n^{\circ} 26$, de 17 de junho de 2013. Dispõe sobre o atendimento da alimentação escolar aos alunos da educação básica no âmbito do Programa Nacional de Alimentação Escolar - PNAE. Brasília, $2013 d$.

Disponível em:

<http://www.fnde.gov.br/fnde/legislacao/resolucoes/item/4620resolu\%C3\%A7\%C3\%A3o-cd-fnde-n\%C2\%BA-26,-de-17-de-junho-de2013 >. Acesso em: 27 jun. 2013.

DAHRENDORF, R. O conflito social moderno: um ensaio sobre a política da liberdade.São Paulo: Zahar; Universidade de São Paulo, 1992.

DAHRENDORF, R. Sociedade e liberdade: para uma análise sociológica do presente. Brasília: Editora Universidade de Brasília, 1981. (Coleção Pensamento Político).

DINIZ, P. Conexões agroecológicas em rede: o diálogo entre alimentação escolar e agricultura familiar na Lapa-PR. 2014. 186f. Dissertação (Mestrado em Segurança Alimentar e Nutricional) - Programa de Pós Graduação em Segurança Alimentar e Nutricional, Universidade Federal do Paraná, Curitiba, 2014.

DUBET, F. Sociologia da experiência. Lisboa: Seuil, 1994.

FORNAZIER, A. Inserção de produtores rurais familiares de regiões com baixa dinâmica econômica para o mercado da alimentação escolar. 2014. Tese (Doutorado em Economia) - Instituto de Economia, Universidade Estadual de Campinas, Campinas, 2014.

GHIZELINI, A. A. M. Atores sociais, agricultura familiar camponesa e o espaço social. 2010. Tese (Doutorado em Sociologia) - Programa de Pós-Graduação em Sociologia, Universidade Federal do Paraná, Curitiba, 2010. 
GIDDENS, A. As consequências da modernidade. São Paulo: Editora Unesp, 1991.

GRISA, C. Políticas públicas para a agricultura familiar no Brasil: produção e institucionalização das ideias. 2012. 280f. Tese (Doutorado em Desenvolvimento, Sociedade e Agricultura) - Programa de Pós Graduação de Ciências Sociais em Desenvolvimento, Agricultura e Sociedade, Universidade Federal Rural do Rio de Janeiro, Rio de Janeiro, $2012 . \quad$ Disponível em: $<$ http://www.mstemdados.org/sites/default/files/2012\%20Tese-CatiaGrisa.pdf $>$. Acesso em: 15 jun. 2015.

PEIXINHO, A. M. L. A trajetória do Programa Nacional de Alimentação Escolar no período de 2003-2010: relato do gestor nacional. Ciência \& Saúde Coletiva, Rio de Janeiro, v. 18, n. 4, p. 909-916, 2013.

SARAIVA, E. B. et al. Panorama da compra de alimentos da agricultura familiar para o Programa Nacional de Alimentação Escolar. Ciênc. Saúde Coletiva, [S.I.],v. 18, n. 4, p. 927-935, out./nov. 2013.

SEN, A. Desenvolvimento como liberdade. São Paulo: Companhia das Letras, 2000.

SILVA, D. W. Produzindo prerrogativas de cidadania:o acesso da agricultura familiar à política de fornecimento de produtos para a alimentação escolar. 2010. Tese (Doutorado em Desenvolvimento Rural) - Programa de Pós-Graduação em Desenvolvimento Rural, Universidade Federal do Rio Grande do Sul, Porto Alegre, 2015.

TRICHES, R. M. Reconectando a produção ao consumo: a aquisição de gêneros alimentícios da agricultura familiar para o Programa de Alimentação Escolar. 2010. Tese (Doutorado em Desenvolvimento Rural) - Programa de Pós-Graduação em Desenvolvimento Rural, Universidade Federal do Rio Grande do Sul, Porto Alegre, 2010. Disponível em:

$<$ http://www.ufrgs.br/pgdr/dissertacoes_teses/arquivos/doutorado/PG DR_D_031_ROZANE_TRICHES.pdf >. Acesso em: 21 maio 2015. 
TRICHES, R. M; FROELICH, E.;SCHNEIDER, S. Relações de produção e consumo: a aquisição de produtos da agricultura familiar para o Programa de Alimentação Escolar no município de Dois Irmãos (RS). In: SCHNEIDER, S.;

TRICHES, R. M.; SCHNEIDER, S.Desestruturar para construir: interfaces para a agricultura familiar acessar o programa de alimentação escolar. Revista Estudos Sociedade e Agricultura, Rio de Janeiro, v. 20, p. 66105, 2012.

TRICHES, R. M.; SCHNEIDER, S.Alimentação escolar e agricultura familiar: reconectando o consumo à produção. Revista Saúde e Sociedade, [S.I.], v. 19, n. 4, p. 933-945, 2010 a.

TRICHES, R. M.; SCHNEIDER, S.Reconstruindo o elo perdido: a reconexão da produção e do consumo de alimentos através do Programa de Alimentação Escolar no município de Dois Irmãos (RS). Revista Segurança Alimentar e Nutricional, Campinas, v. 17, p. 1-15, 2010 b.

TURPIN, M.E. A alimentação escolar como fator de desenvolvimento local por meio do apoio aos agricultores familiares. Revista Segurança Alimentar e Nutricional, Campinas, v. 16 (Supl. 2), p. 20-42, 2009.

TURPIN, M. E. A Alimentação escolar como vetor de desenvolvimento local e garantia da segurança alimentar. 2008. Dissertação (Mestrado em Desenvolvimento Econômico) - Instituto de Economia, Universidade Estadual de Campinas, 2008. Disponível em:

<http://www.eco.unicamp.br/docdownload/monografias/Maria_Elena_T urpin.pdf $>$. Acesso em: 11 maio 2015.

Submetido em 29/05/2016

Aprovado em 20/08/2016

\section{Sobre os Autores}

Danielle Wagner

Dra em Desenvolvimento Rural; Docente da Universidade Federal do Oeste do Pará. Avenida Marechal Rondon, 2370. Santarém, PA. 
Email: danielle.wagner@ufopa.edu.br

\section{Ivaldo Gehlen}

Dr em Sociologia; Docente da Universidade Federal do Rio Grande do Sul. Av. João Pessoa, $31,1^{\circ}$ andar. Porto Alegre/RS.

Email: ivaldo@ufrgs.br

Glauco Schultz3.3. Dr em Agronegócio; Docente da Universidade Federal do Rio Grande do Sul. Av. João Pessoa, $31,1^{\circ}$ andar. Porto Alegre/RS.

Email: schultz@ufrgs.br 